\title{
The Level of Career Success for Talented Students and Its Relation with Gender, Center and Educational Level
}

\author{
Adel Tawfeeq Al Hajjat ${ }^{1}$ \\ ${ }^{1}$ Faculty of Education, University of Jordan, Amman, Jordan \\ Correspondence: Adel Tawfeeq Al Hajjat, Faculty of Education, University of Jordan, Amman, Jordan. E-mail: \\ adelhajjat8@gmail.com
}

Received: November 24, 2016

Accepted: December 30, 2016

Online Published: April 29, 2017

doi:10.5539/ies.v10n5p197

URL: https://doi.org/10.5539/ies.v10n5p197

\begin{abstract}
The aim of this study is to recognize the level of career success for talented students who are graduates from programs of talented individuals in Jubilee School in Amman city and pioneering center for talented individuals in Salt city. The sample of the study includes (162) graduates from the mentioned programs. Also the study aimed to know the level of career success with gender variable and the kind of center that presents the program.

To achieve the objectives of the study, the researcher prepared a scale of career success which contains five dimensions (psychological dimension, social, economic, mental features and work environment) and these dimensions are distributed on (66) paragraphs. Indications of sincerity and invariance of tool were extracted and the scale was applied on individuals of the sample by three ways: (direct interview, phone call and e-mail). To extract the results, the following elements were calculated: arithmetic means, standard deviations, regression analysis, correlation coefficients and analysis of two-way and multiple variances.

The results of the study indicated that the talented individuals of the sample showed high level in career success according to the used scale, the results also showed that the level of career success for females was greater than the males and the results indicated that the career success for the individuals who are graduates from Jubilee School was greater than the career success for individuals who are graduates from leading center for talented students in Salt.
\end{abstract}

Keywords: career success, talented students, academic achievement, pioneering enrichment centers, the jubilee school

\section{Introduction}

Some individuals in society have special abilities and they are called talent or excel. If these abilities are discovered early and if experts either in home or in school or even in society take care of them with support then they will be developed and they will have a great matter, but if nobody notice these abilities then they will vanish and disappear and the person who have these abilities will be like people who are obscure in society and the whole society will lose this grant divine that gave a lot, but people didn't use it well (Shoffner \& Newsome 2001). The talented one or superior is the individual who has a willing or non-normal ability or special performance among colleagues in one domain or more domains which are appreciated by society, especially in mental superiority and creative thinking and academic achievement and skills and special abilities and he is the one who needs a special educational caring which cannot be offered by the school in the normal Curriculum (Perrone, Ksiazak, Wright, \& Crane, 2010).

The high intelligence and superiority in cognitive skills are fundamental elements which can guarantee the success of individual in school education and university education, also in career success in future.If suitable circumstances and opportunities are available, then talented might be scientists and leaders of society in the future (Campbell, \& Feng, 2010) The high academic achievement is considered as one of the main criterions in revealing talents, but the danger of this kind that specify the mental superior is: There are talented students who don't achieve significant success in academic achievement and this category became frequent phenomenon and certain in lots of studies (Mayes \& Hines 2014). The high academic achievement in school is considered as important indicator for talented and passing university stages with high percentages as Paterson and his colleagues indicated in their study which focused on a large group of talented students in school according to the 
evaluations of teachers. There was a significant percentage of students from their study sample, these students had finished their university study successfully (Peterson, Canady, \& Duncan, 2012). Also talented students show high success in professional sides when they graduate from university despite the kinds of these professions (Pyryt, 1992).

The one who thinks about individuals who have high positions in the world and in various countries especially developed ones will realize that they are graduates from prestigious universities which don't accept anyone except distinguished individuals from good reputation schools and approved results, and these students wouldn't be accepted in universities without having admission tests and special conditions which are not achieved by anyone except distinguished individuals (Watters, 2010).

A lot of studies discussed the issue of functional success because it has obvious effect on the extent of individual feeling for psychological comfort and personal achievement, but in general people differ in their definition of functional success with specific way, but the researcher adopts the definition that specify the functional success with accumulation of psychological outcomes and positive process which arising from individual's experiences and this makes him satisfied in general about what he does at work and many specialists mentioned it (Birasnav, Al Merbati, Chaudhary, \& Rangnekar, 2013; Ngo, Foley, Ji, \& Loi, 2014; Uuisiautti \& Matta, 2011; Russ-Eft, Dickson, \& Levine, 2008; Wright, Jenkins, \& Murdock, 2012; Al-Shabatat, Abbas, \& Ismail, 2011; Robertson, 2014; Kamarulzaman \& Ibrahim, 2012; Kamarulzaman \& Nordin, 2012).

No doubt that the skill of learners and their academic achievement depends on many biological, cultural, social and psychological factors. The scientist Louis Turman clarified in his longitudinal study (a group of 1, 528 talented students and superiors on Stanford Scale for intelligence and who got (+IQ 135) for more than 20 years, that these individuals showed a great distinction in their academic achievement and functional success in future (American Counsel of Teaching, ACT, 2009).

\subsection{Literature Review}

When revising the previous literature, we would find many researchers who tried to find an answer for the following question: Does high IQ guarantee a success for individual in his scientific and practical life? note that some studies answered: yes significantly (McGarrah, 2014; Mayes \& Hines 2014; Fiebig \& Beauregard, 2010; Peterson, 2002; Parris et al., 2010; Taylor, 1995; McClarty, 2015). But others answered: There is no guarantee for this and there are some cases which contradict the logic because this might not happen even if the individual has high IQ, he cannot even guarantee the success in school (Gross, 2006; Abdravikova, Akhmadullina, \& Singatullova, 2014; Renzulli, 2012; Smith, 2006).

McClarty (2015) made analytical correlated study aimed to know the effect of superiority and talent in elementary schools and high schools and it's relation with university outcomes and on their behavior in it, the author described them and said they live on fast line, The sample of the study contained (213) students from both genders and who are characterized as superiors and they had the required tests to make sure that they achieved the conditions of the study like mental abilities test for California State (CMAT) as well as other local tests. The results showed that academic superiority and talent make a change in performance and averages for talented students in school and university study, their university grades were relative to their school grades. The comprehensive revision of educational literature which is done by two researchers, Campbel and Feng (2010) indicated that developing the competition between distinct students and superiors to have a kind of students who are able to success and who can be reliable in future.

Two scientists found that accumulated programs of academic superiority centers and the competition that happens inside them are considered as options which don't have any negative impacts on superior students from academic and biological sides or any other problem related to social adaptation or emotion for these students, also the outcomes of these centers are distinct with their success in different scientific sides.

Courville and DeRouen (2009) made a longitudinal study which lasted for 10 years and aimed to recognize the impact of mental superiority on life choices for a group of talented women, they were (126) ladies and they were among the highest $10 \%$ in youths program for high abilities in math (CHOICE). Data were collected by using two questionnaires, one for post high school and other for post college and it contained 24 pages, they were open questions and multiple choices. The results of the study indicated that there is obvious variance on taken decisions in different aspects of life like the kind of university study and the name of the university and specializations that they chose and results showed that there are special social relations and having a family and success at work which they have done after 14 years from the beginning of the study. In general, the amount of success in marriage, education, career and standard of life were same as they wanted before and they had a dream about it when they were youths and teenagers and it was discussed at the beginning of the study. 
Parris et al. (2010) did a study aimed to follow the professional development and mental change for talented individuals who join the labor market through long study which lasted for 4 years. The sample of the study contained 43 students, their IQ is $(+160)$ from America and Germany. One of the objectives of the study was studying the social level for graduates and the effect of parents on their professional decisions, the results of the study clarified that talented students are special with their ability of the right selection for jobs which guarantee high level of social status and ability of girls to choose non- traditional jobs in their societies, they were more creative in the specialization which guarantee excellence and social progress, also the jobs that they chose were belong to the kinds that need more studies and academic work after graduation, so they can get more promotions and financial and moral gains, Furthermore the study confirmed the role of professional guideline for this category of students and more than ordinary students.

Margrain (2010) aimed in her study to know the best instructional exercises which can be given to talented and superior individuals to help them to develop successful professional life and to recognize the most important problems which might face them in their way for healthy and successful life. there was a follow up for graduates after many years to know the extent of achieving program's objectives and results showed that superiors are affected by family guidelines from parents or brochures which are distributed by universities and students can know the available specializations in universities, then they link them with status of people who work these kinds of jobs in society. The study showed that superior individuals usually have a success in professions which they choose and they get more promotions and incremental of salaries comparing with non-superiors who might enter work places with them at the same time. According to the study, the most important problem that affects superiors at work is working inside rooms and closed offices and commitment with specified working hours and routine, whereas these individuals prefer field work and labs and studies which open the space for them to move freely without restrictions of time and place. In general, the professional guideline provided good results to get rid of problems that face superiors and warrant functional success to achieve their ambitions.

\subsection{Jordanian Experiences in the Field of Education and Caring for Talented Individuals}

There is a marked incremental for caring of superiors in Jordan during the last quarter in the 20th century, whereas the actual start of caring for this category appeared in 1982 when the idea of establishing Pioneering Salt (city in Jordan) Center was emerged for talented students. The most prominent mission for this center is discovering talented students and offering advanced levels of privileged experiences in Science, Math and Both languages Arabic and English, but the following few years showed the insistence of administrators and those who are responsible in Jordan to support this initiative and to vary the offered services for this valuable category from sons of kingdom and depending on variety of accumulation manners http://www.moe.gov.jo.

\subsubsection{Pioneering Enrichment Centers}

The history of this organization refers to the start of eighties from past century when the first center of this kind was established in Salt city in cooperation with Salt development cooperation and university of Jordan and ministry of education. The purpose is to reinforce students consciousness for fundamental knowledge through enrichment programs in languages, science, math and computer. Because of success of the experience, the ministry of education established other three centers in other governances in 1996/1997. After that they were developed to be seven centers at the beginning of new millennium (brochures of Pioneering center for excellence-Salt).

\subsubsection{The Jubilee School}

It is considered as a leading model in the Arab World, it was established in 1993 in cooperation with ministry of education after 16 years from announcement history about this idea, Opening this school was a qualitative addition for the movement of educational development in Jordan. Jubilee School has two fundamental goals and it seeks to achieve them:

- Offering comprehensive educational program for school students who were chosen on the basis of sufficiency and ability and according to the best available subjective chosen manners.

- Jubilee High School offers a program for talented and superior students from tenth grade until the end of high school. The program is limited on students of scientific branch and they were chosen carefully among hundreds of candidates from different areas in the kingdom. The school has a high degree of independence in it's educational, administrative and funding programs with supervision of senior officials and specialists who work as a board of trustees or body of administrators http://www.cee.edu.jo 


\subsubsection{Schools of King Abdullah for Excellence}

The work of this program started at the beginning of academic year 2001-2002, and there are three school in governorates, Zarqa, Irbid and Salt. These schools serve the category of talented students in grades from seventh grade until high school.

\subsubsection{The Programs of Resources Room}

The program aims to offer special services for talented students in ordinary schools These programs (resources rooms) are existed in some public schools (ministry of education-Jordan).

\subsection{Statement of Problem}

The researches confirm the importance of offered programs for those who have excellence and mental superiority and to build an individual who is able to success and to have progress and presenting special contributions and modern thoughts in both scientific life and practical life, but still there are few local and Arabic studies in this domain and they don't reach to level of ambitions which led the organizers of these private educational centers to serve this category, the organizers of centers for talented and distinct individuals want to know the extent of ability for their centers and programs to contribute for labor market with capable individuals who can get functional success and professional creativity and to serve the country in the best possible way, they also want to know the best programs and subjects which they have to offer for their students and the extent of their effectiveness in their professional future as well as the required methods for guidelines and directions to help students in the optimum selection for careers and scientific domains and practical domains. This will offer a functional success for them and effective contribution in building the society.

\subsection{Questions of the Study}

- -What's the level of functional success for the study sample of graduates from distinction programs in Jordan?

- $\quad$-Does the level of functional success for the sample of the study differs according to gender, and kind of program?

\section{Research Methodology}

\subsection{Material Studied}

\subsubsection{The Population of the Study}

The population of the study contains graduates of distinction programs and they were (422) students from Jubilee School and (397) students from pioneering center, the total is (819) individuals.

\subsubsection{The Sample of the Study}

The sample of the study contains graduates from distinction and excellence programs in pioneering center in Salt city and Al Jubilee School in Amman city for first three years from the time when both programs were opened. They were (162) individuals. The number of individuals from Jubilee School was (91) and (71) from pioneering center, boys were (104) and girls were (58).

\subsection{Tools of the Study}

To achieve the objectives of the study, the researcher used a scale of career success which is prepared by the researcher. The researcher developed a scale to evaluate the career success for the sample of the study through reading and looking at related educational literature and revising a group of international scales in this domain. The indication of sincerity and invariance scale were extracted, so in final image it contained 66 paragraphs distributed on five dimensions (psychological dimension, social dimension, economical dimension, mental features dimension, work environment dimension).

Each paragraph contains five levels and grade of answering level on paragraphs scale according to lickert scale (totally agree, agree, not sure, don't agree, and totally disagree).

The researcher applied the tool on the sample of the study by many methods and depending on the desire and the place of individuals of the sample; these methods are (personal interview, phone interview, e-mail).

\section{Results}

To answer the first question which is related to level of functional success for the study sample of graduates from excellence programs in Jordan, the first table shows arithmetic mean and standard deviation and the rank and the grade for level of functional success for individuals of the study as a whole. 
Table 1. Arithmetic mean and standard deviation for functional success for sample

\begin{tabular}{lcccc}
\hline Domain & Arithmetic Mean & Standard Deviation & Rank & grade \\
\hline Overall degree for career success & 3.36 & 0.45 & 1 & Medium \\
\hline
\end{tabular}

Table 1 shows that the overall degree for career success is medium with Arithmetic Mean of 3.36 and Standard Deviation of 0.45 , but this wasn't the success that the establishers of the talented programs wanted.

To answer the second question which is related to the extent of difference for functional success level for individuals of the sample according to gender variable (male, female) and the kind of program (Jubilee School, Pioneering Center) the table shows: Arithmetic Mean and Standard Deviation and Rank and Grade for level of functional success for the sample according to the mentioned variables.

Table 2. The variables of gender and kind of program

\begin{tabular}{lcccccccccc}
\hline \multirow{2}{*}{ Individuals of the sample } & $\begin{array}{c}\text { Arithmet } \\
\text { ic Mean }\end{array}$ & $\begin{array}{c}\text { Standard } \\
\text { Deviation }\end{array}$ & Rank & $\begin{array}{c}\text { Total of } \\
\text { squares }\end{array}$ & $\begin{array}{c}\text { Degrees of } \\
\text { Freedom }\end{array}$ & $\begin{array}{c}\text { Average of } \\
\text { Squares }\end{array}$ & F value & grade \\
\hline \multirow{2}{*}{ gender } & Boys & 3.29 & 0.47 & 2 & 0.188 & 0.188 & 1.045 & 1.774 & Medium \\
& Girls & 3.33 & 0.41 & 1 & 0.442 & 0.442 & 3.202 & 1.254 & Medium \\
\multirow{2}{*}{ prog } & Jubilee & 3.45 & 0.43 & 1 & 0.957 & 0.957 & 5.609 & $* 0.019$ & Medium \\
& Pioneering & 3.39 & 0.42 & 2 & 0.047 & 0.047 & 0.229 & 0.633 & Medium \\
\hline
\end{tabular}

Statistically significant at level $*(a=0.05)$.

Table 2 shows that there are no differences which are statistically significant in the total degree for functional success in gender variable, F value for gender equal (1.774) and it's not statistically significant at the level $(a=0.05)$ but girls showed higher level than boys in answering questions of the study (3.33 versus 3.29).

Table 2 also shows that there are differences which are statistically significant in the total degree for functional success for kind of center variable to Jubilee School, F value $=0.019$ and it's statistically significant at level $(\mathrm{a}=0.05)$ versus $(0.633)$ for pioneering center, also in the answer average on scale of functional success $(3.39$ versus 3.45).

\section{Discussion}

Referring to the results of first question which is related to career success for individuals of the sample as a whole, the results showed that all individuals were (Arithmetic Mean 3.36, Standard Deviation 0.45) on the scale of functional success which is prepared by the researcher. This indicates that talented individuals show medium level in functional success. According to the researcher, this refers to non-successful preparation programs and achieving goals of programs for talented people in Jordan generally and considering the philosophy of establishing these programs and what they seek to do at first place. Focusing on the results of second question which is related to functional success for individuals according to gender variable and kind of program, the results showed that the level of functional success for individuals of the sample, for girls (Arithmetic Mean 3.33 and Standard Deviation 0.41) and for boys (Arithmetic Mean 3.29 and Standard Deviation 0.47). Although the differences are not statistically significant but they showed bigger effect for programs on girls more than the boys and their feeling of career success and having benefits from offered services in educational programs which are made for talented individuals in excellence centers as well as girls show more commitment for work and they appreciate their role in serving the society more than boys. Results also showed that level of career success for individuals sample of graduates from Jubilee School was (Arithmetic Mean 3.45 and Standard Deviation 0.43), whereas the level of functional success for individuals sample of graduates from Pioneering Center in Sult city was (Arithmetic Mean 3.39 and Standard Deviation 0.42) and these differences are statistically significant, according to the researcher, the reason of this result: graduates from Jubilee School were prepared with more efficient way because they study full hours in it, in contrast to pioneering center where students attend only few hours and after actual attendance in ordinary schools.

\section{References}

Abdravikova, A., Akhmadullina, R., \& Singatullova, A. (2014). The implementation of project and research activities in working with gifted children in terms of school. English Language Teaching, 7(12), 54-59. 
Al-Shabatat, A., Abbas, M., Ismail, H. (2011). The direct and indirect effects of environmental factors on nurturing intellectual giftedness. International Journal of special education, 26(2), 18-28.

American Counsel of Teaching ACT. (2009). The path to career success: high school achievement, certainty of career choice, and college readiness make a difference. ACT, Inc, U.S.A.

Birasnav, M., Al Merbati, H., Chaudhary, R., \& Rangnekar, S. (2013). Predictors of career success among government employees. Management and Labor Studies, 34(4), 517-529. https://doi.org/10.1177/0258042X13509745

Campbell, J., \& Feng, A. (2010). Comparing adult longitudinal studies of productivity for gifted American. Gifted Child Quarterly, 38(3), 28-41.

Courville, K., \& DeRouen, Z. (2009). Minority bias in identification and assessment of gifted students: A historical perspective and prospects for the future. Journal for the Education of the Gifted, 25(3), 84-99.

Fiebig, J., \& Beauregard, E. (2010). Longitudinal change and Maternal influence on occupational aspirations of gifted female American and German adolescents. Journal for the Education of the Gifted, 34(1), 45-67. https://doi.org/10.1177/016235321003400103

Gross, M. (2006). Exceptionally gifted children: long-term outcomes of academic acceleration and non acceleration, Journal for the Education of the Gifted, 29(4), 404-429. https://doi.org/10.4219/jeg-2006-247

Heslin, P. (2003). Self- and other-referent criteria of career success. Journal of Career Assessment, 11(3), 262-286. https://doi.org/10.1177/1069072703254500

Karmarulzaman, W., \& Ibrahim, M. (2012). What predicts job satisfaction in Malaysia. 2nd Southeast Asia Psychology Conference.

Karmarulzaman, W., \& Nordin, M. (2012). Job satisfaction: the comparison between school leavers and college graduates. 2nd international conference on arts, Malaysia.

Margrain, V. (2010). Narratives of young gifted children. Kairaranga, 11(2), 33-38.

Mayes, R., \& Hines, E. (2014). College and career readiness for gifted African American girls. Interdisciplinary Journal of Teaching and Learning, 4(1), 31-42.

McGarrah, M. (2014). Lifelong Learning skills for college and career readiness: An annotated bibliography. American Institutes for Research. October 2014.

Ngo, H., Foley, S., Ji, M., \& Loi, R. (2014). Linking gender role orientation to subjective career success: the mediating role of giftedness. Journal of Career Assessment, 22(2), 290-303. https://doi.org/10.1177/1069072713493984

Parris, G., Owens, D., \& Johnson, T. (2010), Addressing the career development needs of high-achieving African American high school students. Journal for the Education of the Gifted, 33(3), 417-436.

Perrone, K., Ksiazak, M., Wright, S., \& Crane, A. (2010). Multigenerational giftedness: perceptions of giftedness across three generations. Journal for the Education of the Gifted, 33(4), 606-627. https://doi.org/10.1177/016235321003300407

Peterson, J. (2002). A longitudinal study of post-high-school development in gifted individuals at risk. The Journal of Secondary Gifted Education, 14(1), 6-18.

Peterson, J., Canady, K., \& Duncan, N. (2012), Positive life experiences: Cross-setional, longitudinal study gifted graduates. Journal for the Education of the Gifted, 35(1), 81-99. https://doi.org/10.1177/0162353211432042

Pyryt, M. (1992). Career development for the gifted and Talented. 6th Canadian Symposium, 3, 145-182.

Renzulli, J. (2012). Reexamining the role of gifted education and talent development for the 21st century. Gifted Child Quarterly, 56(3), 150-159. https://doi.org/10.1177/0016986212444901

Robertson, H. (2014). Life satisfaction of former-military, second-career changers. JNAAC, 9(1), 3-13.

Russ-Eft, D., Dickson, P., \& Levine, R. (2008). Certification and career success: A leads project. Journal of Career Assessment, 15(4), 4-22.

Shoffner, M., \& Newsome, D. (2001), Identity development of gifted female adolescents: the influence of career development, age, and life-role salience. The Journal of Secondary Gifted Education, 7(4), 201-211.

Smith, J. (2006). Examining the long-term impact of High achievement during the transition to high school. The 
Journal of Secondary Gifted Education, 17(4), 211-221.

Taylor, L. (1995). Undiscovered editions: Fostering the talents of vocational- technical students. Educational Research and Evaluation, 13, 245-259.

Watters, M. (2010). Addressing the career development needs of high-achieving African American high school students. Journal for the Education of the Gifted, 33(3), 417-436. https://doi.org/10.1177/016235321003300306

Westover, J. (2012). Personalized pathways to success. Leadership, May/June 2012. 12-38.

Wright, S., Jenkins, M., \& Murdock, J. (2012). Career development among firse-year college students and academic success. Journal of Career Development, 40(4), 292-310. https://doi.org/10.1177/0894845312455509

Zhou, W., Sun, J., Yanjun, G., Li, Y., \& Pan, J. (2012). Criteria of career success among Chinese employees. Journal of Career Assessment, 21(2), 265-277. https://doi.org/10.1177/1069072712471302

\section{Copyrights}

Copyright for this article is retained by the author(s), with first publication rights granted to the journal.

This is an open-access article distributed under the terms and conditions of the Creative Commons Attribution license (http://creativecommons.org/licenses/by/4.0/). 